\title{
Carbon Dioxide Mitigation by Microalgal Photosynthesis
}

\author{
Mijeong Lee Jeong, ${ }^{*}$ James M. Gillis, ${ }^{\dagger}$ and Jiann-Yang Hwang ${ }^{\dagger}$ \\ Plant Biotechnology Research Center, Forest Resources and Enwironmental Science, \\ Aichigan Technological Lnversit, Houghton, 1119931 , LSA

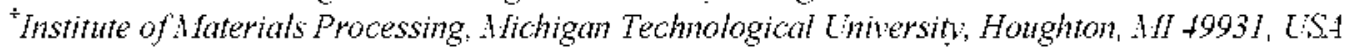 \\ Received Januarv 23, 2003
}

\begin{abstract}
Algal growth studies of Chlore/la strains were conducted in a batch mode with bench type experiments. Carbon dioxide fixation rates of the following green microalgae were detemined: Chlorella sp. H84. Chlorella sp. A2. Chlorella sorokiniana UTEX 1230. Chlorella wilgaris, and Chlorella purenoidosa. C. wilgaris, among other strains of microalgae, showed the highest growth rate ( 1.17 optical density/ $/ 5$ days). Cultivating conditions for C. vitgaris that produced the highest growth rate were at concentrations of $243 \mu \mathrm{g} \mathrm{CO}_{-} / \mathrm{mL}, 10 \mathrm{mM}$ anmonia. and $1 \mathrm{mM}$ phosphate. with an initial $\mathrm{pH}$ range of $7-8$
\end{abstract}

Key Words : $\mathrm{CO}_{2}$ fixation. Chlorella vilgaris. BioScrubber

\section{Introduction}

With global warming resulting from increased atmospheric carbon dioxide $\left(\mathrm{CO}_{2}\right)$ levels. this issue has beconte a major focus of the environmental agenda. The United States $\mathrm{CO}_{2}$ production is on a rise from the already approximately 5.56 billion tons per year from coal-buming power plants. ${ }^{1}$ This amount of $\mathrm{CO}_{2}$ is equivalent to about $21 \%$ of the entire world's production. The flue gases' composition from power plants changes slightly with the specific fuel type and the amount of air used in combustion. Typical flue gas compositions with different fuel sources are approximately $10 \%{ }^{2} \mathrm{CO}_{2}$ flue gas concentrations of up to $20 \%$ have been measured when coal is burned. ${ }^{3}$

Among many attempts to reduce the quantity of $\mathrm{CO}_{2}$ in the atmosphere. biotechnology of using nicroalgae in a photobioreactor has extensively been studied since the beginuing of the $1990 \mathrm{~s}$. With the biological approach, $\mathrm{CO}_{2}$ is converted into algal biomass and then into value-added products such as proteins, vitamins. food. and feeds. However. processes for biological flue gas cleanups are still under development and there are problems such as low productivity of the biomass and inefficient $\mathrm{CO}_{2}$ utilization to meet industry's challenge. Currently, there is no practical technology available in this direction.

The concept of using outdoor macroalgal cultures in ponds, lakes. oceans or land has been proposed as a method to reduce $\mathrm{CO}_{2}$ emissions. ${ }^{4}$ However. it is difficult to optimize algal growth in an open pond. resulting in low productivity of the process. For commercial operations. about $2 \%$ of the United States land would have to be converted to these ponds in order to capture enough $\mathrm{CO}_{2}$ to make a difference in the $\mathrm{CO}_{2}$ emissions in this country. Therefore, the applicability of this approach becomes questionable.

While outdoor systems mainly struggle with low productivity.

"To whom correspondence should be addressed. Tel: +1-906487-2878; Fax: +1-906-487-2915; e-mail: njeong tantu.edu closed photobioreactors can achieve higher productivity without causing any further envirommental problems. ${ }^{5.6}$ Closed photobioreactors can more readily control environmental conditions (temperature, oxygen. and nutrients) than open cultures. However. they cannot effectively control $\mathrm{CO}_{2}$ from exhaust gases because $\mathrm{CO}_{2}$ is usually bubbled through the reactor with the excess $\mathrm{CO}_{2}$ being emitted to the atmosphere, and the $\mathrm{CO}_{2}$ concentration and temperature vary with the combustion conditions of the power plant

The ultimate goal of our research program is to develop an industrial BioScrubber as a closed photobioreactor system that can effectively and efficiently reduce green house gases from fossil-fueled power plants. In the BioScrubber system, we have a Bioreactor unit and a Gas Scrubber unit (not discussed in the present paper). In a Scrubber. $\mathrm{CO}_{2}$ is absorbed into algal culture medium. In this approach there will be no excess $\mathrm{CO}_{2}$ emitted to the environment. In a bioreactor unit, microalgal strains are cultivated in the $\mathrm{CO}_{2}$ absorbed medium from the scrubber. We started to select microalgae that could be cultivated under high $\mathrm{CO}_{2}$ concentration. In this paper, as the first step of series, preliminary assessment of algae for fixing $\mathrm{CO}_{2}$ will be our focus. Detailed discussions on a gas scrubber system will be incorporated into the next paper of this series.

\section{Materials and Method}

Medium and cultivation conditions. Chlorella sorokiniana UTEX 1230 was obtained from the University of Texas, Austin. Chlorella vilgaris and Chlorella pyrenoidosa were purchased from Carolina Biological Supply Co. (Burlington, $\mathrm{NC}$ ). Chlorella sp. H84 and Chlorella sorokiniona A2 were obtained from the Research Institute of Innovative Teclnology for the Earth (RITE, Tokyo. Japan).

ASM-1 medium ${ }^{l}$ for $C$. pyrenoidosa and $C$. sorokiniana UTEX 1230 and $\mathrm{N}-8$ medium ${ }^{7}$ for $C$. vilgaris were used. ASM1 medium was composed of $(\mathrm{g} / \mathrm{L}) \mathrm{Na}_{2} \mathrm{HPO}_{4} \cdot 2 \mathrm{H}_{2} \mathrm{O}$. 0.26; $\mathrm{KH}_{2} \mathrm{PO}_{4} .0 .740 ; \mathrm{CaCl}_{2}$. 0.01: FeEDTA, 0.01; $\mathrm{MgSO}_{4} \cdot 7 \mathrm{H}_{2} \mathrm{O}$, 
$0.05 ; \mathrm{KNO}_{3}, 1.0$; and trace element stock solution, $1.0 \mathrm{~mL} / \mathrm{I}$.. $\mathrm{N}-8$ medium was composed of (g/L,) NaNO, 0.17 ; $\mathrm{MgSO}_{4} \cdot 7 \mathrm{H}_{2} \mathrm{O}, 0.024 ; \mathrm{MgCl}_{2}, 0.019 ; \mathrm{CaCl}_{2}, 0.022 ; \mathrm{K}_{2} \mathrm{HPO}_{4}$. $0.017 ; \mathrm{Na}_{2} \mathrm{HPO}_{4}, 0.014$; and trace element stock solution, $1.0 \mathrm{ml} / / \mathrm{L}$. Cells were activated by inoculating a loop of a slant culture into $100 \mathrm{~mL}$, of the medium in a $250-\mathrm{mL}$. Frlenmeyer flask and were precultured under continuous illumination at room temperature $\left(20-25^{\circ} \mathrm{C}\right)$ for a week, $\mathrm{MC}$ medium ' was used for cultivating Chlorella sp. H84 and C. sorokiniana $\mathrm{A} 2$. $\mathrm{MC}$ medium was composed of $\left(\mathrm{g} / \mathrm{l}\right.$ ) $\mathrm{KNO}_{4}$. $1.25 ; \mathrm{KH}_{2} \mathrm{PO}_{4}, 1.25 ; \mathrm{MgSO}_{4} \cdot 7 \mathrm{H}_{2} \mathrm{O}, 1.25 ;$ Fe solution, $1 \mathrm{~mL}$; A5 solution (composed of $\mathrm{H}_{3} \mathrm{BO}_{3}, \mathrm{MnSO}_{4} \cdot 4 \mathrm{H}_{2} \mathrm{O}, 7 \mathrm{nSO}_{4} \cdot 7 \mathrm{H}_{2} \mathrm{O}$, $\mathrm{CuSO}_{4} \cdot 5 \mathrm{H}_{2} \mathrm{O}, \mathrm{Na}_{2} \mathrm{MoO}_{4} \cdot 2 \mathrm{H}_{2} \mathrm{O}, \mathrm{H}_{2} \mathrm{O}$ ), $1 \mathrm{ml}$., They were precultured and then mass cultured in a warm water bath at a temperature of $40^{\circ} \mathrm{C}$ as recommended by Sakai et al.$^{3}$

For an inorganic carbon source both $\mathrm{CO}_{2}$ gas and sodium bicarbonate salt were employed; a prescribed ratio (using a mass flow controller) of $\mathrm{CO}_{2}$ mixed in air was supplied to the cultures through an air diffuser (Aqua-Tech, Moorpark, CA). Also a known amount of bicarbonate salt was dissolved in the regular medium. Four cool-white fluorescent lamps (EconF40I,W/RS/EW, 34 Watt, Philips, Underwriters laboratories lnc.) were used as the light source at 3500 lux (maximum). Algae were cultured at room temperature, except for Chlorella sp. $\mathrm{H} 84$ and C. sorokiniana A2.

Analytical methods. The light intensity was measured by an analog photometer (Sper Scientific l.td., Scottsdale, A7.). Cell counting was performed with a hemacytometer (Hausser Scientific, Horsham, PA). Optical density (OD) was measured by means of counting cell population of microalgae with a UV/Vis Spectrophotometer (model Lambda 3B, Perkin Elemer) at $680 \mathrm{~nm}$ based on a linear relationship between optical density and cell density. The $\mathrm{pH}$ levels of the cultivated solutions were measured by an Accumet $925 \mathrm{pH}$ ion Meter (Fisher Scientific) and adjusted with $1 \mathrm{M} \mathrm{HCl}$ and $1 \mathrm{M} \mathrm{NaOH}$.

\section{Results and Discussion}

Assessment of microalgae. Among studied microalgae, C. vulgaris showed the highest cell growth during 5 days of batch cultivation (Figure 1). (hhlorella sp. H84 and Chlorella sp. A2 were the next fast growing strains, and C. prenoidosa and C. sorokiniana U'LEX 1230 showed the slowest cell growth.

When C. migaris was cultivated in our culturing media using the solutions obtained from our scrubbing operation, equivalent or higher growth rate to that given in the literature could be obtained (data not shown). This established the fundamental technical feasibility of our BioScrubber approach.

Although most organisms cannot survive under high temperatures, certain kinds of microalgae can thrive in hot springs. Their tolerance to high temperature could be beneficial to the biological $\mathrm{CO}_{2}$ fixation, since the flue gas from power plants is about $40^{\circ} \mathrm{C}$ after desulfurization and nitrogen oxide removal. In our study the growth of Chlorella sp. $\mathrm{H} 84$ and $\mathrm{C}$. sorokiniana $\mathrm{A} 2$ at $40^{\circ} \mathrm{C}$ was slower than at

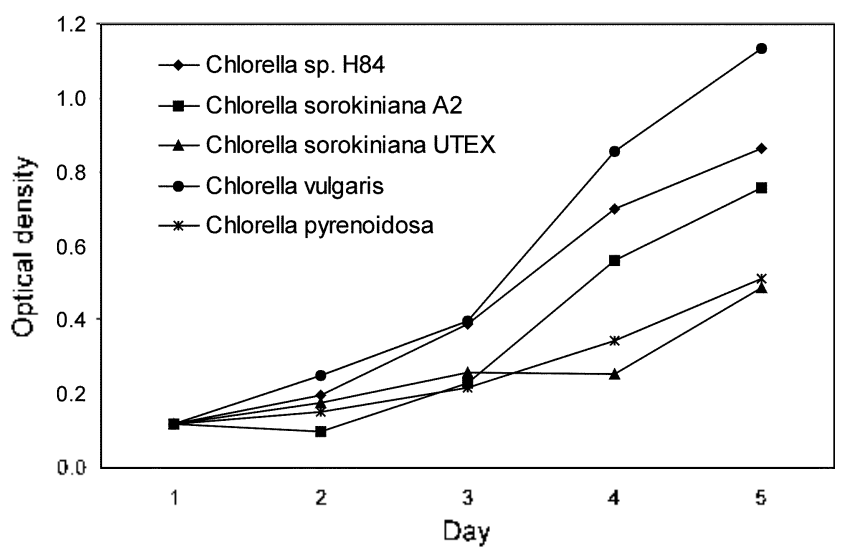

Figure 1. Different growth rates of microalgate.

$25^{\circ} \mathrm{C}$, as approximately $250 \mathrm{ppm}$ (or $\mu \mathrm{g} / \mathrm{mL}$.) of carbon dioxide was supplied to all cultures. This result is not same to the result of Sakai et al, "Investigation of $\mathrm{CO}_{2}$ fixation by microalgate who can survive at the temperature higher than $40{ }^{\circ} \mathrm{C}$ is under development in our laboratory with algal strains collected from hot springs.

Growth characteristics of Chlorella vulgaris. Further studies were performed to characterize the growth of $C$. vulgaris. The optimum starting cell density was investigated and the results are shown in Figure 2. With a cell density of $1.775 \times 10^{3}$ (cells/mL), C. vilgatis grew very slowly. At the range of $1.775 \times 10^{4}$ to $10^{5}$ cells, $C$ vilgaris grew faster than with the lower initial cell density. Therefore, all cultivation of the alga was started at or above these cell densities.

Figure 3 shows the growth rate of $\mathrm{C}$. vulgaris at different concentrations of $\mathrm{CO}_{2}$. Without any addition of $\mathrm{CO}_{2} \mathrm{C}$. vulgaris grows very slowly by only utilizing $\mathrm{CO}_{2}(0.035 \%$ in air). Both $10 \%(\mathrm{v} / \mathrm{v})$ and $20 \%(\mathrm{v} / \mathrm{v})$ of $\mathrm{CO}_{2}$ (mixed with air) showed similar results with medium growth rates. With $30 \%$ (viv) of $\mathrm{CO}_{2}$ in air, the growth rate was higher after four days than the growth rate obtained under the other conditions four days after the cultivation was initiated. Higher than $30 \%$ of $\mathrm{CO}_{2}$ concentration was not tested because the expected composition of $\mathrm{CO}_{2}$ from the flue gas is about $15 \%$.

To simplify the cultivating procedure, known amounts of sodium bicarbonate salt was dissolved into the standard

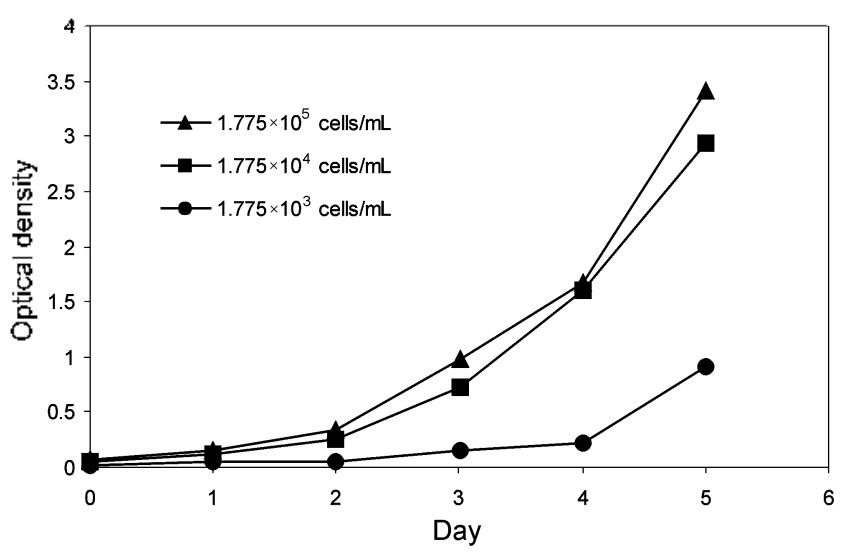

ligure 2. Chlorella valgaris growth with dillerent starting cell densities. 


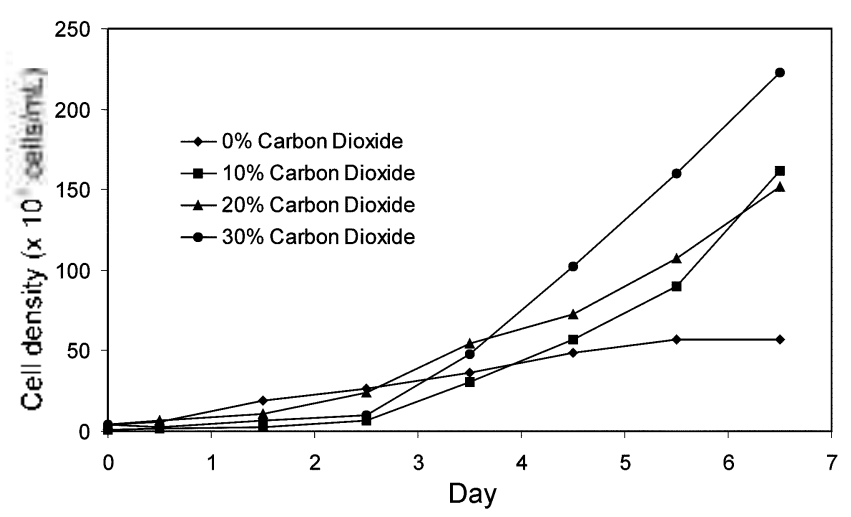

Figure 3. Chorella velgaris growth with different $\mathrm{CO}_{2}$ concentration (vol \%) in air.

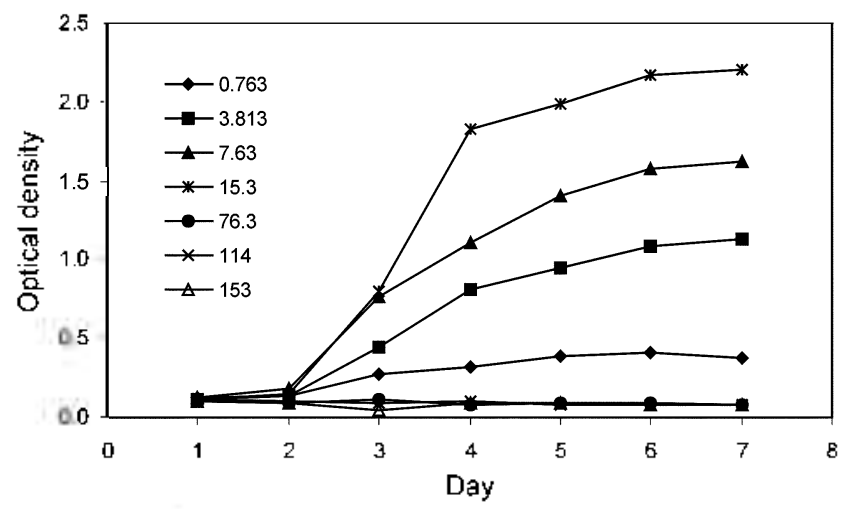

Figure 4. Effects of $\mathrm{CO}_{2}$ concentrations on the growth of $\mathrm{Chlore} / \mathrm{l}$. whlgaris. The legends describe the $\mathrm{CO}_{2}$ concentration as sodium bicarbonate $\left(\mathrm{Nall}_{\mathrm{ICO}} \mathrm{CO}_{3} \mathrm{ppm}\right.$

medium as an inorganic carbon source. As can be seen in Figure 4 , at a concentration of $15.3 \mathrm{ppm}$ of bicarbonate (equivalent to $243 \mathrm{ppm}$ as $\mathrm{CO}_{2}$ ), the (C. vilgaris strain exhibited its fastest growth rate ( 1.8 optical density/4 days).

At the optimum concentration of $\mathrm{CO}_{2}$, concentrations of other species in the algal broth were calculated by a software program, called MINEQL ${ }^{40}$ (calculation program based on thermodynamics). It was found that at the conditions of $\mathrm{pH}$ 5.7 (initial $\mathrm{pH}$ of (.. vilgaris cultivation) and $243 \mathrm{ppm}$ of $\mathrm{CO}_{2}$. the algal broth contains $4.61 \times 10^{-3} \mathrm{M}$ of aqueous $\mathrm{CO}_{2}\left(\mathrm{H}_{2} \mathrm{CO}_{3}\right)$ and $8.92 \times 10^{-4} \mathrm{M}$ of bicarbonate $\left(\mathrm{HCO}_{3}^{-}\right)$. This indicates that C. vtlgaris utilizes both aqueous $\mathrm{CO}_{2}(\mathrm{ca} .80 \%)$ and bicarbonate $(c a .20 \%)$ for its biological $\mathrm{CO}_{2}$ fixation.

The effects of nitrogen $(\mathrm{N})$ and phosphorus ( $\mathrm{P}$ ) nutrients on $($. . vilgaris were investigated. The cell growth was higher and faster with $\mathrm{N}-8$ medium containing both $\mathrm{N}$ and $\mathrm{P}$ than a medium without $\mathrm{N}$ and $\mathrm{P}$ (Figure 5). The optimum concentrations of phosphate and ammonia were determined for $C$. vtlgaris at the optimized $\mathrm{CO}_{2}$ level. Similar C'. vulgaris growth was resulted with both ammonium ion and nitrate ion for a nitrogen source (data not shown). It was, therefore, decided to use ammonium hydroxide $\left(\mathrm{NH}_{4} \mathrm{OH}\right)$ as the nitrogen source for all $\mathrm{C}$. milgaris cultures, since $\mathrm{NH}_{+} \mathrm{OH}$ is much less expensive than $\mathrm{KNO}_{3}$, which is of common nitrogen source.

The highest cell growth of C. milgaris was achieved with

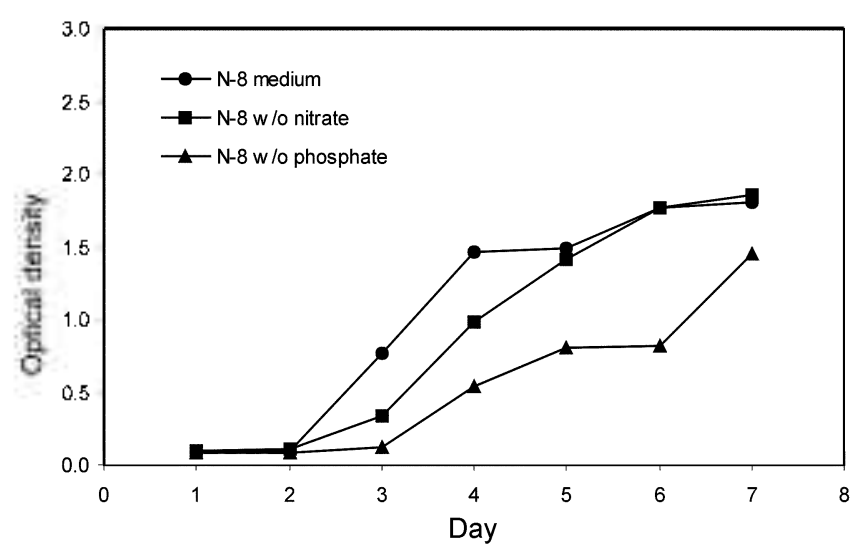

Figure 5. Liffects of nitrate and phosphate ions on the growth of Chlorella vulgaris at an optimized $\mathrm{CO}_{2}$ concentration.

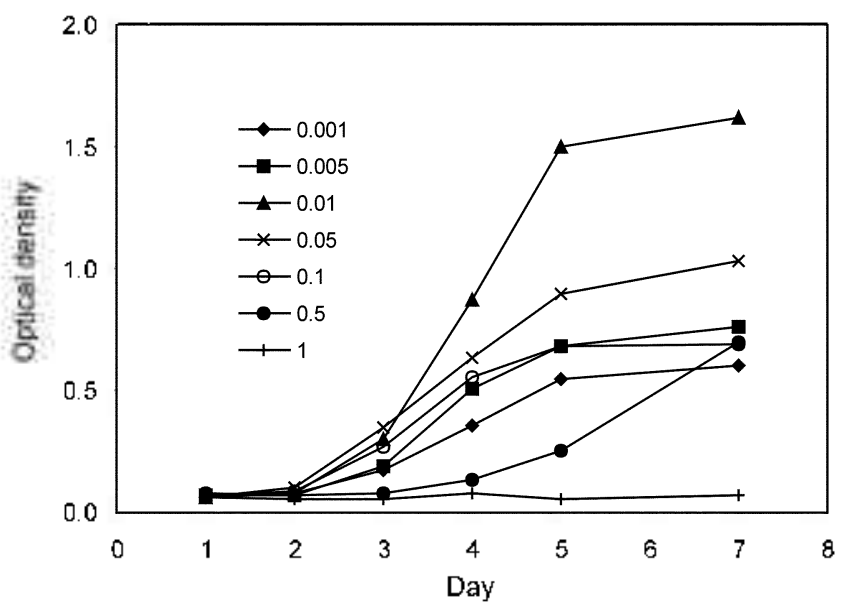

Figure 6. Optimizing ammonia conontration for a Chlowella vutgaris culture. The legend indicales the concentration of ammonia as Molarity (M).

$10 \mathrm{mM}$ of ammonia and $1 \mathrm{mM}$ of phosphate (Figures 6 and 7). There was a great increase in optical density between day 4 and 5, while other cultures showed slower growth. A very high concentration of ammonia ( $1 \mathrm{M}$ ) and phosphate (100 $\mathrm{mM}$ ) appeared to inhibit the (. vulgaris growth.

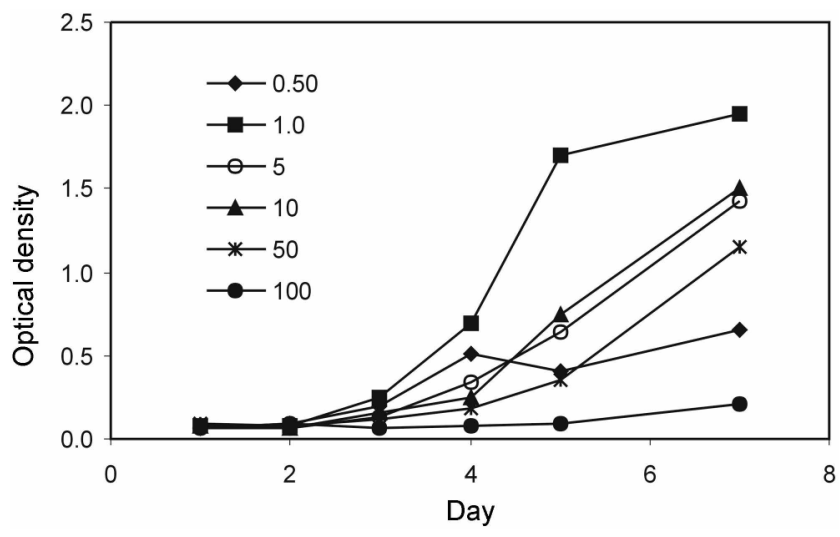

Figure 7. Optimizing phosphate concentration for a Chlorella vulgaris culture. The legend indicates the concentration of phosphate as $\mathrm{mM}$. 


\section{Conclusions}

Among five algal strains tested in the present study, Chlowella wlgamis showed the highest growth rate. Therefore. this alga was selected as our primary candidate for our BioScrubber system, whose detailed design and testing are under way in our laboratory. $C$. nilgoris produces a range of high-value substances. and the biomass itself can be used in aquaculture for feeding purposes and as an additive for animal feed that is rich in vitamins. deal of potential for a successful BioSrubber approach. Investigation of new candidates of different algal strains (including marine algae) for this study is now under way in our laboratory.

Acknowledgement. Funding for this research was provided by the US Department of Energy.

\section{References}

1. Apel. W. A.: Walton. M. R.: Dugan. P. R. Fuel Processing Teclmolog, 1994. 40.139.

2. Mustacchi. C. Armenante. P: Cena, V. Carbon Dioxide Disposal in the Ocean: Williams, J.. Ed.: Proceedings of IASA Workshop. 1978: $\mathrm{p} 283$

3. Sakai. N.: Sakamoto. Y.. Kishimoto. N.: Chihara. M.: Karube. I. Chlorella Stains From Springs Tolerant to High Temperatur? and High CO.: International Marine Biotechnology Conference. 1994.

4. Guterman. H.: Yaakov, S. B. Biotechol Bioeng. 1990. 35. 417.

5. Nishikeawa. N. Amsterdam Meeting. 1992.

6. Laws, E. A.; Taguchi. S.; Hirata. J.: Pang. L. Biotechol Bioeng 1988. 32.140

7. Javantnardian. P.: Palsson. B. O. Biotechol. Bioeng. 1991.38. 1182.

8. De Pauw. N.: Perscone. G. 1ficro-algae for Aquacultwe: Borowitzha. L. J.. Ed.; Cambridge University Press: Cambridge, 1988; p 197.

9. Becker. E. W. Aicro-algae for Human and inmal Constmption? Borowitzka. M. A.. Borowitzka, L. J.. Eds.: Cambridge University Press: Cambridge. 1988: p 153. 